\title{
The relationship between insulin resistance, adiponectin and C-reactive protein and vascular endothelial injury in diabetic patients with coronary heart disease
}

\author{
WEIHUA XU, MINGHUI TIAN and YANJU ZHOU \\ Department of Emergency, Weifang People's Hospital, Weifang, Shandong 261041, P.R. China
}

Received November 15, 2017; Accepted June 27, 2018

DOI: $10.3892 /$ etm.2018.6407

\begin{abstract}
Relationship between insulin resistance, adiponectin and C-reactive protein and vascular endothelial injury in diabetic patients with coronary heart disease (CHD) was investigated. Clinical data of 72 patients with diabetes mellitus diagnosed in Weifang People's Hospital (Weifang, China) from October 2015 to January 2017 were retrospectively analyzed. Thirty patients were combined with CHD and 42 patients were not. There were 43 males and 29 females. General information and clinical data including age, sex, duration of diabetes mellitus, biochemical indicators, fasting insulin levels, CRP, insulin resistance index, arterial lesions of coronary angiography and Gensini scores were collected. The levels of FINS, FPG,HOMA-R and CPR were significantly higher, and the level of ADPN was significantly lower in diabetes complicated with CHD group than that without CHD group $(\mathrm{P}<0.05)$. Incidence of single coronary artery disease and mild coronary lesion were significantly lower, and incidences of double and triple lesions were significantly higher in diabetes complicated with CHD group than that without $\mathrm{CHD}$ group $(\mathrm{P}<0.05)$. Gensini score was significantly higher in diabetes complicated with CHD group than that without CHD group $(\mathrm{P}<0.05)$; Analysis of the correlation showed that $\mathrm{CRP}(\mathrm{r}=0.422, \mathrm{P}=0.001)$ and insulin resistance index $(\mathrm{r}=0.828, \mathrm{P}=0.001)$ were positively correlated with Gensini score, while the adiponectin level was negatively correlated with Gensini score $(r=-0.719, \mathrm{P}<0.001)$. Logistic regression analysis showed that FINS, ADPN, HOMA-R, CPR, duration of diabetes mellitus and BMI had independently predictive value for diabetes complicated with $\mathrm{CHD}(\mathrm{P}<0.05)$. Serum adiponectin, insulin resistance and CPR levels are closely related to diabetes mellitus combined with coronary heart disease, and can affect the degree of vascular endothelial injury in coronary heart disease.
\end{abstract}

Correspondence to: Ms. Yanju Zhou, Department of Emergency, Weifang People's Hospital, Weifang, Shandong 261041, P.R. China E-mail: hnrrry9003@163.com

Key words: diabetes, coronary heart disease, adiponectin, insulin resistance, C-reactive protein

\section{Introduction}

With the growth of the aging population, and changes in genetic and environmental factors and social life style, the incidence of diabetes has shown an increasing trend worldwide (1). A recent study showed that the number of diabetic patients in China exceeds 30 million and most of them are over 45 years old. Diabetes mellitus is a chronic metabolic disorder characterized by disorder of blood glucose regulation, and it may cause cardiovascular and cerebrovascular diseases (2). Coronary heart disease (CHD) and diabetes share many risk factors, which in turn increase the incidence of CHD in diabetic patients (2). The most common cause of type 2 diabetes is insulin resistance, which is caused by the reduced physiological effects of insulin. When the secretion of insulin cannot meet the basic needs of the human body, diabetes will occur, so insulin resistance is closely related to the occurrence and development of diabetes, and also affects the occurrence of atherosclerosis (3). Adiponectin protein (ADPN) is synthesized by adipocytes, and plays an important role in reducing blood sugar, regulating lipid, resisting atherosclerosis, and anti-inflammatory activities (4). It is generally believed that atherosclerosis is an inflammatory disease. Vascular injury leads to an inflammatory reaction. C-reactive protein (CRP) is an inflammatory reaction protein (5). At present, it is generally believed that the common pathogenesis of diabetes and coronary heart disease is inflammation, and inflammation is the common precursor of both diabetes and coronary heart disease (6). Therefore, inflammation may be the key to link the development of diabetes and coronary atherosclerosis. Therefore, understanding the correlation between serum adiponectin, CRP levels, insulin resistance and vascular injury may help to reduce blood sugar, protect target organs, and also provide new ideas for the treatment of diabetic patients with CHD (7).

\section{Patients and methods}

General information. A total of 72 diabetic patients who were diagnosed in Weifang People's Hospital (Weifang, China) from October 2015 to January 2017 were selected. Clinical data of the patients were retrospectively analyzed. A total of 30 patients were complicated with CHD and 42 patients were not. The patients included 43 males and 29 females, 


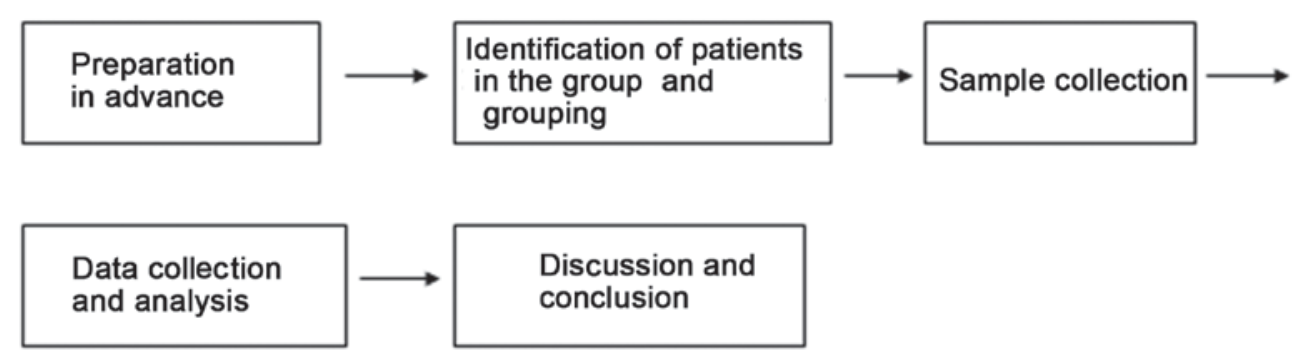

Figure 1. Flow diagram.

and the age ranged from 55 to 75 years, with a mean age of $60.5 \pm 7.6$ years. All patients met the diagnostic criteria for type 2 diabetes established by WHO in 1997. Degree of artery stenosis was higher than $70-75 \%$. Inclusion criteria were: patients diagnosed with diabetes; no drugs that affected the results were used in the prior 2 weeks before experiment; no history of alcohol abuse; no hypercortisolism; no hypopituitarism. Exclusion criteria were: patients who were treated with insulin or insulin sensitizer in the prior 2 weeks; patients with severe hematologic disorders; patients with severe heart, liver and kidney dysfunction; patients with cancer; patients with incomplete clinical data. The study was approved by the Ethics Committee of Weifang People's Hospital (Weifang, China) and informed consents were signed by the patients or their guardians. The flow diagram is shown in Fig. 1.

Methods. Clinical data of all patients were retrospectively analyzed. Clinical data included age, sex, weight, height, duration of diabetes, BMI, blood sugar control situation, and methods of blood sugar control (type of drug, dosage and methods used). All patients were fasted and not allowed to drink water for $10 \mathrm{~h}$ overnight before extracting fasting peripheral blood. Related biochemical indicators in serum were determined. Fasting plasma glucose (FPG) was measured by glucose oxidase method; HbAlc was measured using HbAlc analyzer; with the kits provided by Beijing Kepu Science and Technology Co., Ltd. (Beijing, China) level of ADPN was determined by enzyme-linked immunosorbent assay (ELISA) and FINS level was determined by radioimmunoassay. The remaining biochemical indicators including total cholesterol (TC), triglyceride (TG), low density lipoprotein (LDL) and high density lipoprotein (HDL) were detected using an automatic biochemical analysis provided by Hitachi (Tokyo, Japan). Insulin resistance index (HOMA-R) was calculated as FINSA * FPG/22.5. CRP inflammatory cytokine in serum was detected with immune turbidimetric assay using reagents and instruments provided by Shandong Bainus Medical Instrument Co., Ltd. (Shandong, China).

The degree of arterial stenosis was evaluated by Gensini scoring method, and the vascular endothelial injury was evaluated synthetically (8). The judgement of the degree of arterial stenosis was as follows: the degree of stenosis below $50 \%$ was mild, 50 to $75 \%$ was moderate, more than $75 \%$ was severe, and complete stenosis was occlusion. The criteria for determining the arterial coefficient of the lesion were as follows: left main artery lesion (5 points); proximal segment of left anterior descending branch lesion (2.5 points); middle segment of left anterior descending branch lesion (1 point); far-end of
Table I. Calculation of Gensini scores.

\begin{tabular}{|c|c|c|c|}
\hline Stenosis & Scores & Affected arteries & Scores \\
\hline$<25 \%$ & 1 & Left main coronary artery & 5 \\
\hline $25-50 \%$ & 2 & $\begin{array}{l}\text { Left anterior descending artery or } \\
\text { proximal end of circumflex artery }\end{array}$ & 2.5 \\
\hline $51-75 \%$ & 4 & $\begin{array}{l}\text { Middle region of left anterior } \\
\text { descending artery }\end{array}$ & 1.5 \\
\hline $76-90 \%$ & 8 & $\begin{array}{l}\text { Distal end of left anterior } \\
\text { descending artery }\end{array}$ & 1 \\
\hline $91-99 \%$ & 16 & $\begin{array}{l}\text { Middle or distal end of left } \\
\text { circumflex artery }\end{array}$ & 1 \\
\hline $100 \%$ & 32 & $\begin{array}{l}\text { Right coronary artery and small } \\
\text { branches }\end{array}$ & $1,0.5$ \\
\hline
\end{tabular}

left anterior descending branch lesion (1 point); left circumflex branch lesion (1 point); right coronary artery disease (1 point); small branches $(0.5 \mathrm{~min})$. The total score of coronary artery stenosis was obtained by multiplying the degree of coronary artery stenosis in different branches of coronary artery and the corresponding coefficient (Table I).

Statistical analysis. SPSS 19.0 statistical software (IBM Corp., Armonk, NY, USA) was used to process all data. Measurement data were expressed as (mean $\pm \mathrm{SD}$ ), and were analyzed by t-test, and classified data were analyzed by $\chi^{2}$ test. Correlations between factors were analyzed by Pearson's correlation analysis. Logistic analysis was carried out to analyze related risk factors. $\mathrm{P}<0.05$ was considered to indicate a statistically significant difference.

\section{Results}

Comparison of general information between diabetes complicated with and without CHD group. No significant differences in age, sex, TC, TG, LDL and HDL were found between diabetes complicated with and without CHD group ( $\mathrm{P}>0.05)$. However, the duration of diabetes, BMI and $\mathrm{HbAlc}$ in diabetes complicated with CHD group were significantly higher than those in the without CHD group $(\mathrm{P}<0.05)$ (Table II).

Comparison of levels of ADPN, CRP, FPG, HOMA-R, arterial lesions, Gensini scores between diabetes complicated with and without CHD group. Levels of FINS, FPG, HOMA-R and CPR were significantly higher, while ADPN level was 
Table II. Comparison of general information between diabetes complicated with and without CHD group.

\begin{tabular}{lccr}
\hline Items & $\begin{array}{c}\text { With CHD } \\
(\mathrm{n}=30)\end{array}$ & $\begin{array}{c}\text { Without CHD } \\
(\mathrm{n}=42)\end{array}$ & P-value \\
\hline Age (years) & $62.37 \pm 6.91$ & $61.52 \pm 5.87$ & 0.624 \\
Sex (male/female) & $19 / 11$ & $24 / 18$ & 0.127 \\
Duration of & $13.72 \pm 2.08$ & $6.67 \pm 1.90$ & $<0.001$ \\
diabetes (years) & & & \\
BMI $\left(\mathrm{kg} / \mathrm{m}^{2}\right)$ & $26.81 \pm 2.42$ & $21.46 \pm 2.96$ & 0.032 \\
HbA1c $(\%)$ & $10.55 \pm 1.42$ & $7.43 \pm 0.72$ & $<0.001$ \\
TC $(\mathrm{mmol} / \mathrm{l})$ & $5.79 \pm 1.03$ & $4.92 \pm 1.08$ & 0.525 \\
TG $(\mathrm{mmol} / \mathrm{l})$ & $1.92 \pm 1.08$ & $1.88 \pm 0.68$ & 0.065 \\
LDL $(\mathrm{mmol} / \mathrm{l})$ & $3.06 \pm 0.92$ & $2.98 \pm 0.51$ & 0.522 \\
HDL $(\mathrm{mmol} / \mathrm{l})$ & $1.45 \pm 0.53$ & $1.39 \pm 0.26$ & 0.079 \\
& & & \\
\hline
\end{tabular}

Table III. Comparison of levels of ADPN, CRP, FPG and HOMA-R between diabetes complicated with and without CHD group.

\begin{tabular}{lrrr}
\hline Items & $\begin{array}{c}\text { With CHD } \\
\text { group }(\mathrm{n}=30)\end{array}$ & $\begin{array}{l}\text { Without CHD } \\
\text { group }(\mathrm{n}=42)\end{array}$ & P-value \\
\hline FINS $(\mathrm{mI} \mu / \mathrm{l})$ & $14.21 \pm 2.72$ & $9.82 \pm 2.73$ & 0.003 \\
FPG $(\mathrm{mmol} / \mathrm{l})$ & $11.35 \pm 1.97$ & $8.43 \pm 0.88$ & 0.021 \\
ADPN $(\mu \mathrm{g} / \mathrm{ml})$ & $3.96 \pm 1.88$ & $8.51 \pm 2.59$ & $<0.001$ \\
HOMA-R & $7.45 \pm 1.43$ & $3.98 \pm 1.26$ & 0.001 \\
CPR $(\mathrm{mg} / \mathrm{l})$ & $5.39 \pm 1.45$ & $2.40 \pm 0.81$ & 0.001 \\
\hline
\end{tabular}

Table IV. Comparison of types of arterial lesions between diabetes complicated with and without CHD group.

\begin{tabular}{|c|c|c|c|}
\hline $\begin{array}{l}\text { Types of lesions } \\
\text { and degree }\end{array}$ & $\begin{array}{c}\text { With } \\
\text { CHD group } \\
(n=30)\end{array}$ & $\begin{array}{c}\text { Without } \\
\text { CHD group } \\
(n=42)\end{array}$ & P-value \\
\hline \multicolumn{4}{|l|}{ Type } \\
\hline Single artery lesion & $15.02 \%$ & $53.22 \%$ & 0.001 \\
\hline Double artery lesion & $29.75 \%$ & $19.34 \%$ & 0.032 \\
\hline Triple artery lesion & $55.23 \%$ & $27.44 \%$ & 0.001 \\
\hline \multicolumn{4}{|l|}{ Degree } \\
\hline Mild $(\leq 50 \%)$ & 0 & $88.09 \%$ & $<0.001$ \\
\hline Moderate (50-74\%) & $50 \%$ & $11.91 \%$ & 0.001 \\
\hline Severe $(75-99 \%)$ & $30 \%$ & 0 & $<0.001$ \\
\hline Occlusion (100\%) & $20 \%$ & 0 & $<0.001$ \\
\hline Gensini scores (points) & $35.62 \pm 21.38$ & $9.74 \pm 15.78$ & $<0.001$ \\
\hline
\end{tabular}

significantly lower in diabetes complicated with CHD group than that in the without CHD group $(\mathrm{P}<0.05)$ Table III).

Incidence of single artery lesion in diabetes complicated with CHD group was $15.02 \%$, which was lower than that in the without CHD group (52.22\%). However, the incidence of
Table V. Logistic regression analysis of risk factors for diabetes complicated with CHD.

\begin{tabular}{lccc}
\hline Items & P-value & OR value & $95 \%$ CI \\
\hline Age & 0.108 & 1.094 & $0.987,1.156$ \\
Sex & 0.847 & 0.912 & $0.101,6.826$ \\
Duration of diabetes & 0.016 & 7.954 & $1.917,27.156$ \\
BMI & 0.005 & 7.347 & $1.918,23.154$ \\
FPG & 0.044 & 1.029 & $0.955,1.117$ \\
HbA1c & 0.039 & 1.001 & $0.927,1.109$ \\
TC & 0.025 & 1.423 & $0.576,3.572$ \\
TG & 0.526 & 1.447 & $0.465,4.487$ \\
LDL & 0.022 & 2.654 & $0.964,7.117$ \\
HDL & 0.957 & 0.079 & $0.445,22.317$ \\
FINS & 0.024 & 1.047 & $0.996,1.312$ \\
ADPN & 0.001 & 1.005 & 0.9971 .033 \\
HOMA-R & 0.032 & 1.065 & $0.959,1.115$ \\
CPR & 0.029 & 1.054 & $0.984,1.065$ \\
\hline
\end{tabular}

Table VI. Comparison of Gensini scores between diabetes complicated with and without CHD group.

\begin{tabular}{lccc}
\hline & $\begin{array}{c}\text { With CHD } \\
\text { group } \\
(\mathrm{n}=30)\end{array}$ & $\begin{array}{c}\text { Without CHD } \\
\text { group } \\
(\mathrm{n}=42)\end{array}$ & P-value \\
\hline Gensini & $35.62 \pm 21.38$ & $9.74 \pm 15.78$ & $<0.001$ \\
\hline
\end{tabular}

double and triple artery lesion in diabetes complicated with CHD group were 29.75 and $55.23 \%$, respectively, which was higher than that in the without CHD group. The ncidence of mild coronary lesion in diabetes complicated with CHD group was $0 \%$, which was lower than in the without CHD group, while the incidence of moderate, severe and occlusive disease was 50, 30 and 20\%, respectively, which were significantly higher than that in the without CHD group $(\mathrm{P}<0.05)$ (Tables IV and V).

Comparison of arterial lesions in diabetic patients with and without CHD. The incidence of single artery lesion in diabetic patients with CHD was $15.02 \%$, which was significantly lower than that in diabetic patients without CHD (52.22\%). However, the incidence of double and triple artery lesion (29.75\% and $55.23 \%$, respectively) was significantly higher in diabetic patients with CHD than those without CHD. The incidence of mild lesion in diabetic patients with CHD was 0 , while the incidence of moderate and severe lesions as well as occlusion were significantly higher in diabetic patients with CHD (50, 30 , and $20 \%$, respectively) than those without CHD $(\mathrm{P}<0.05)$. Gensini score of diabetic patients with CHD was significantly higher than those without CHD (Table VI).

Correlation between levels of ADPN, CRP and HOMA-R and Gensini scores. There was a positive correlation between CRP $(r=0.422, P=0.001)$, insulin resistance index $(r=0.828$, 


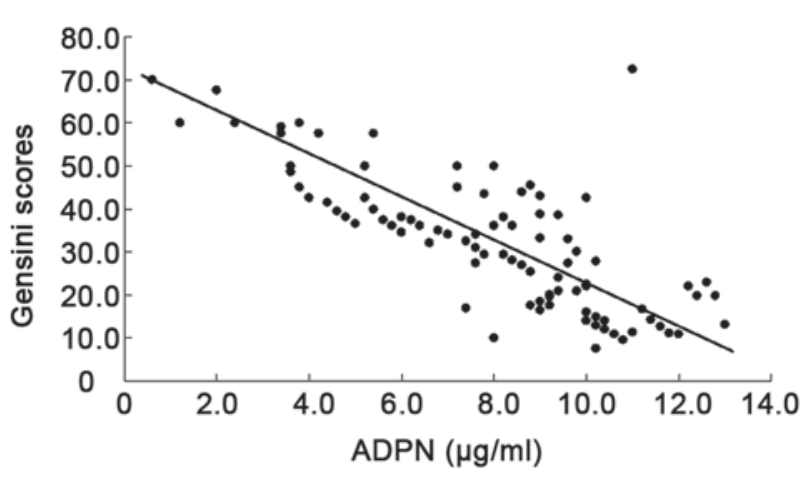

Figure 2. Correlation between ADPN and Gensini scores.

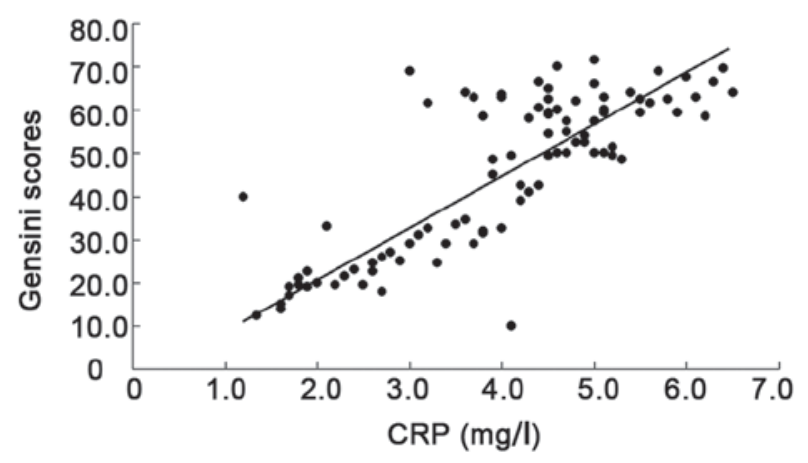

Figure 3. Correlation between CRP and Gensini scores.

$\mathrm{P}=0.001)$ and Gensini score, but a negative correlation between adiponectin and Gensini score $(r=-0.719, \mathrm{P}<0.001)$ (Figs. 1-3).

Logistic regression analysis of risk factors for diabetes complicated with CHD. Sex, age, TG and HDL were not risk factors for diabetes complicated with CHD, while FINS, ADPN, HOMA-R, $\mathrm{CPR}$, duration of diabetes, BMI, FPR and HbA1c were independent factors for diabetes complicated with CHD (Table V).

\section{Discussion}

With continuous changes of living environment and eating habits, the incidence of diabetes has reached $10 \%$, which is mostly type 2 diabetes (2). Type 2 diabetes is mainly caused by dysfunction of blood glucose regulation, resulting in impaired function of various target organs and tissues of the whole body. The most common complication of type 2 diabetes is vascular disease, and the basis of the pathogenesis of diabetes-induced vascular disease is atherosclerosis and coronary heart disease (8). Human vascular smooth muscle contains vascular endothelial cells, and these cells synthesize various active substances (such as NO and other substances that can relax blood vessels) required for the normal physiological processes of the body (9). In addition, vascular endothelial cells can protect blood vessels, maintain its stability, and prevent aggregation of white blood cells and platelets (10). Long-term hyperglycemia can directly damage the vascular endothelial cells, promote the aggregation of platelets, leukocytes and other factors (11), increase the number of vascular smooth muscle cells, reduce levels of vasodilators, increase the levels of vasoconstriction factors, and further promote blood vessel endothelial injury (12). On

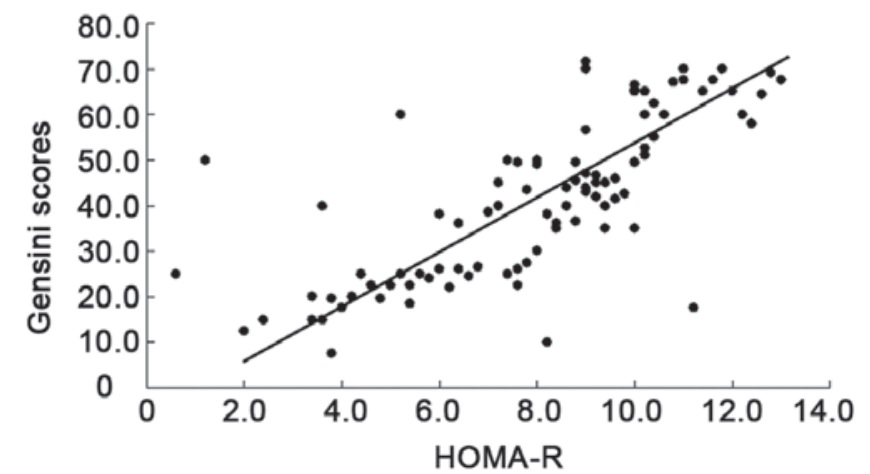

Figure 4. Correlation between HOMA-R and Gensini scores.

the other hand, abnormal serum adiponectin, overexpression of inflammatory cytokines, and insulin resistance are also closely related to atherosclerosis. In patients with diabetes, elevated levels of inflammatory cytokines, increased expression of adhesion molecules, dysregulated vascular regulators, and impaired vascular endothelium eventually lead to atherosclerosis (13).

In this study we found that the CRP level in the diabetic patients with CHD was significantly higher than that in diabetic patients with CHD, which was consistent with previous studies. Insulin resistance may induce dyslipidemia, vascular endothelial cell damage, increased inflammatory response in vivo and hypercoagulable state of the blood system. Studies have shown that each unit increase in insulin resistance index may increase the incidence of CHD by $5 \%$ (10). Adiponectin has become a new hot research issue in recent years. Adiponectin in human body can regulate the lipid level, reduce blood sugar level and protect blood vessels, so as to inhibit atherosclerosis. Adiponectin can also inhibit the expression and secretion of vascular endothelial cell adhesion molecules, such as tumor necrosis factor (14). Studies on serum adiponectin levels in patients with type 2 diabetes, obesity, and their associated metabolic syndrome showed that decline in serum adiponectin is positively correlated with reduced insulin sensitivity (15). With the continuous development of type 2 diabetes, serum adiponectin levels appear to gradually decline, and it has been confirmed that adiponectin within a physiologically normal level can promote fatty acid metabolism and energy consumption of liver tissue cells as well as reduce insulin resistance (16).

Weyer et al (17) detected peripheral serum adiponectin levels, insulin resistance, and body fat composition ratio in a total of 121 Indian and Caucasian people and they found that serum adiponectin levels were negatively correlated with body fat composition ratios and fasting insulin levels, and were positively correlated with insulin sensitivity, suggesting that serum adiponectin concentrations were closely correlated with type 2 diabetes. Results of this study showed that levels of FINS, FPG, HOMA-R and CPR were significantly higher, while ADPN level was significantly lower in diabetic patients complicated with CHD group than that in patients without CHD group. Gensini score was also significantly higher in diabetes complicated with CHD group than that in the without CHD group. Arterial lesions were more severe in diabetes complicated with CHD group than that in the without CHD group. In addition, CRP and insulin resistance index were positively correlated with Gensini score, while adiponectin level was negatively correlated with 
Gensini score, indicating that severity of coronary artery lesions was increased with the decreased level of ADPN, and increased levels of HOMA-R and CRP. Therefore, compared with the diabetic patients without CHD, patients complicated with CHD were found with increased severity of insulin resistance, increased CRP levels and decreased adiponectin levels. Antiinflammatory treatment and increasing adiponectin level are expected to become a new treatment for patients with CHD (18). Wang et al (19) investigate the relationship between insulin resistance, blood glucose, inflammatory cytokines, and cardiovascular events in patients with diabetes mellitus complicated with CHD. However, their study only included CRP. In our study, CRP, interleukin, and tumor necrosis factor were included, and GRACE risk scores were used in risk assessment. Gensini score can be used to intuitively show the degree of coronary artery damage, artery lesion types and degree. However, there are still many deficiencies in our study. Sample size is small, and there is no relevant follow-up study. Correlation study of inflammatory factors is not deep enough. Therefore, future studies with larger number of samples and follow-up are needed.

\section{Acknowledgements}

Not applicable.

\section{Funding}

No funding was received.

\section{Availability of data and materials}

The datasets used and/or analyzed during the present study are available from the corresponding author on reasonable request.

\section{Authors' contributions}

WX conceived and designed the study, as well as drafted the manuscript. MT and YZ collected, analyzed and interpreted the experiment data, as well as revised the manuscript critically for important intellectual content. All authors have read and approved the final manuscript.

\section{Ethics approval and consent to participate}

The study was approved by the Ethics Committee of Weifang People's Hospital (Weifang, China). Signed informed consents were obtained from the patients or their guardians.

\section{Patient consent for publication}

Not applicable.

\section{Competing interests}

The authors declare that they have no competing interests.

\section{References}

1. Nanayakkara G, Kariharan T, Wang L, Zhong J and Amin R: The cardio-protective signaling and mechanisms of adiponectin. Am J Cardiovasc Dis 2: 253-266, 2012.
2. Akishita M, Fukai S, Hashimoto M, Kameyama Y, Nomura K, Nakamura T, Ogawa S, Iijima K, Eto M and Ouchi Y: Association of low testosterone with metabolic syndrome and its components in middle-aged Japanese men. Hypertens Res 33: 587-591, 2010.

3. Barud W, Nasiłowska-Barud A, Sobstyl J, Mieczkowska J, Wójcicka G, Bełtowski J, Myśliński W and Mosiewicz J: Association of stromal-derived factor-1 alpha and endogenous sex hormones in men aged over 50 years with stable coronary artery disease. Adv Med Sci 57: 322-327, 2012.

4. Pant S, Deshmukh A, Gurumurthy GS, Pothineni NV, Watts TE, Romeo F and Mehta JL: Inflammation and atherosclerosis revisited. J Cardiovasc Pharmacol Ther 19: 170-178, 2014.

5. Chew BH, Ghazali SS, Ismail M, Haniff J and Bujang MA: Age $\geq 60$ years was an independent risk factor for diabetes-related complications despite good control of cardiovascular risk factors in patients with type 2 diabetes mellitus. Exp Gerontol 48: 485-491, 2013.

6. van Hamburg JP, Corneth OB, Paulissen SM, Davelaar N, Asmawidjaja PS, Mus AM and Lubberts E: IL-17/Th17 mediated synovial inflammation is IL-22 independent. Ann Rheum Dis 72: 1700-1707, 2013.

7. Kounis NG and Goudevenos JA: Everolimus-eluting versus paclitaxel-eluting stents. Lancet 375: 1161-1162, author reply $1161-1162,2010$

8. Rostami R, Najafi M, Sarami R, Bozorgi A, Soltani M and Salamati P: Gensini scores and well-being states among patients with coronary artery disease: A comparison study. ARYA Atheroscler 13: 205-210, 2017.

9. Uslu S, Kebapçi N, Kara M and Bal C: Relationship between adipocytokines and cardiovascular risk factors in patients with type 2 diabetes mellitus. Exp Ther Med 4: 113-120, 2012.

10. Reilly MP, Rohatgi A, McMahon K, Wolfe ML, Pinto SC, Rhodes T, Girman C and Rader DJ: Plasma cytokines, metabolic syndrome, and atherosclerosis in humans. J Investig Med 55: 26-35, 2007.

11. Stratton IM, Adler AI, Neil HA, Matthews DR, Manley SE, Cull CA, Hadden D, Turner RC and Holman RR: Association of glycaemia with macrovascular and microvascular complications of type 2 diabetes (UKPDS 35): Prospective observational study. BMJ 321: 405-412, 2000.

12. Chanson M and Kwak BR: Connexin37: A potential modifier gene of inflammatory disease. J Mol Med (Berl) 85: 787-795, 2007.

13. Thakore AH, Guo CY, Larson MG, Corey D, Wang TJ, Vasan RS, D'Agostino RB Sr, Lipinska I, Keaney JF Jr, Benjamin EJ, et al: Association of multiple inflammatory markers with carotid intimal medial thickness and stenosis (from the Framingham Heart Study). Am J Cardiol 99: 1598-1602, 2007.

14. Ramli J, CalderonArtero P, Block RC and Mousa SA: Novel therapeutic targets for preserving a healthy endothelium: Strategies for reducing the risk of vascular and cardiovascular disease. Cardiol J 18: 352-363, 2011.

15. Fernandes GS, Fernandez CD, Campos KE, Damasceno DC, Anselmo-Franci JA and Kempinas WD: Vitamin C partially attenuates male reproductive deficits in hyperglycemic rats. Reprod Biol Endocrinol 9: 100-108, 2011.

16. Jalili S, Yousefi R, Papari MM and Moosavi-Movahedi AA: Effect of homocysteine thiolactone on structure and aggregation propensity of bovine pancreatic insulin. Protein J 30: 299-307, 2011.

17. Weyer C, Funahashi T, Tanaka S, Hotta K, Matsuzawa Y, Pratley RE and Tataranni PA: Hypoadiponectinemia in obesity and type 2 diabetes: Close association with insulin resistance and hyperinsulinemia. J Clin Endocrinol Metab 86: 1930-1935, 2001.

18. Krasnodębski P, Opolski G and Karnafel W: Plasma adiponectin levels in acute myocardial infarction and during the postinfarction recovery period in patients with type 2 diabetes mellitus. Kardiol Pol 69: 924-930, 2011.

19. Wang C, Li F, Guo J, Li C, Xu D and Wang B: Insulin resistance, blood glucose and inflammatory cytokine levels are risk factors for cardiovascular events in diabetic patients complicated with coronary heart disease. Exp Ther Med 15: 1515-1519, 2018.

This work is licensed under a Creative Commons Attribution-NonCommercial-NoDerivatives 4.0 International (CC BY-NC-ND 4.0) License. 